\title{
INCREASED PRESSOR RESPONSES TO NICOTINE IN SPONTANEOUSLY HYPERTENSIVE RATS
}

\author{
Takao KUBO and Yoshimi MISU \\ Department of Pharmacology, Yokohama City University School of Medicine. \\ Minami-ku, Yokohama 232, Japan \\ Accepted November 1, 1980
}

\begin{abstract}
Intraventricular administration of nicotine produced a biphasic effect, consisting of an initial rise then a slight fall in blood pressure in unanaesthetized rats. Spontaneously hypertensive rats (SHR) showed increased pressor responses, but these responses were within normal limits in renal hypertensive and DOCA-saline hypertensive rats. The blood pressure response to nicotine in SHR was abolished by intraventricular administration of hexamethonium, but not by atropine given via the same route. Central phentolamine and 6-hydroxydopamine did not affect the pressor response to nicotine. The pressor effect of nicotine in SHR was markedly diminished after removal of the adrenals and abolished after bilateral adrenalectomy plus peripheral 6-hydroxydopamine. These results indicate that the pressor response to intraventricular nicotine is increased in SHR. The pressor effect of nicotine may result from the activation of the central nicotinic receptor sites, which may cause the release of catecholamines both from the adrenal medulla and adrenergic nerve terminals.
\end{abstract}

Brain acetylcholine has been implicated in the central control of cardiovascular function (1-4). However, little information is available concerning the possible involvement of central cholinergic mechanisms in the pathophysiology of arterial hypertension. In a previous study we found that pressor response to intravenous physostigmine was increased in SHR (5).

When injected into a lateral ventricle of the cat brain, nicotine produced a fall in blood pressure (6). Furthermore, superfusion of nicotine at the medullary levels produced both pressor and depressor effects in cats (3). The purpose of the present study was to examine the possible involvement of central nicotinic mechanisms in the maintenance of hypertension in SHR by testing the effect of intraventricular nicotine administration on blood pressure in this strain of rats.

\section{MATERIALS AND METHODS}

Five to 10-month-old female SHR and age-matched normotensive Wistar Kyoto rats (WKR) were used. For the production of renal hypertension and DOCA-saline hypertension, male Wistar rats were used at the age of 5 weeks. Renal hypertension was induced by occlusion of the left renal artery with a silk thread (the two kidney Goldblatt model) (7). For the induction of DOCAsaline hypertension, rats were subjected to left nephrectomy, DOCA (40 mg/kg) was given s.c. twice per week from the 5 th week onwards, and $1 \% \mathrm{NaCl}$ was substituted for 
drinking water (8). Eleven to 13-week-old renal hypertensive rats were used for experiments and compared with age-matched untreated normotensive controls (NR). Rats with an initial mean arterial pressure of over $150 \mathrm{mmHg}$ served as the hypertensive animals.

Two days before the test day, each rat was stereotaxically implanted with one lateral ventricular cannula, under pentobarbitone sodium anaesthesia. This cannula was made of stainless steel tubing $0.7 \mathrm{~mm}$ o.d. The stereotaxic co-ordinates with respect to bregma were posterior $0.5 \mathrm{~mm}$, lateral $2.0 \mathrm{~mm}$ and $4.5 \mathrm{~mm}$ deep from the dura. Intraventricular administration was given through a cannula $0.3 \mathrm{~mm}$ o.d. connected via polyethylene $10 \mathrm{PE}$ tubing to a $25,: 1$ Hamilton syringe. The site of injection was determined at the end of experiments by injection of $5 . .4$ of $1 \%$ Toluidine Blue.

On the morning of experiments, each rat was anaesthetized with ether and the femoral artery and vein were cannulated for the recording of mean arterial pressure and for i.v. administration of drugs, respectively. Blood pressure was measured using a Toyo Meas. pressure transducer (MPU-0.5-290). Electrically integrated values of mean arterial pressure were recorded. Experiments were started $3 \mathrm{hr}$ after surgery, at which time the animals had recovered from the ether anaesthesia. In order to simplify the cardiovascular response to intraventricular or intravenous nicotine administration, peripheral muscarinic receptors were blocked by i.v. methylatropine (1 $\mathrm{mg} / \mathrm{kg}$ ), this agent producing a slight fall in blood pressure $(2-5 \mathrm{mmHg}$ ).

Drugs were dissolved in physiological saline and given i.v.c. in a volume of $5 \mathrm{kl} /$ $100 \mathrm{~g}$ body weight and i. $v$. in a volume of $0.1 \mathrm{ml} / 100 \mathrm{~g}$ body weight. Nicotine was administered i.v.c. at intervals of $90 \mathrm{~min}$.

Drugs used were nicotine tartrate (Wako Pure Chemical.), atropine methyl bromide
(Sigma), atropine sulphate (E. Merck), hexamethonium bromide (Yamanouchi Pharmaceutical Company), phentolamine mesylate (Ciba), 6-hydroxydopamine hydrobromide (Sigma), /-noradrenaline hydrochloride (Sigma) and /-adrenaline bitartrate (Sigma). All doses refer to the free base.

Differences between means were analyzed by Student's t-test, paired when comparing treated and untreated SHR, and unpaired when comparing hypertensive and control rats. At $p$-values below 0.05 the difference was considered significant.

\section{RESULTS}

Vascular response to intraventricularly injected nicotine in experimentally hypertensive and normotensive rats: Intraventricular nicotine (1 and $10 / \mathrm{gg} / \mathrm{kg}$ ) administration in SHR pretreated with i.v. methylatropine produced a biphasic effect that is an initial marked rise then a slight fall in blood pressure (Fig. 1). The pressor response was of short duration, usually lasting no longer than $3 \mathrm{~min}$, while the depressor response lasted 8-20 $\mathrm{min}$. These pressor responses to intraventricular nicotine in SHR were significantly greater than those in control (WKR), while renal hypertensive and DOCA-saline hypertensive rats showed no significant difference in pressor response to nicotine as compared to the normotensive control (NR) (Table 1). Depressor responses of these normotensive

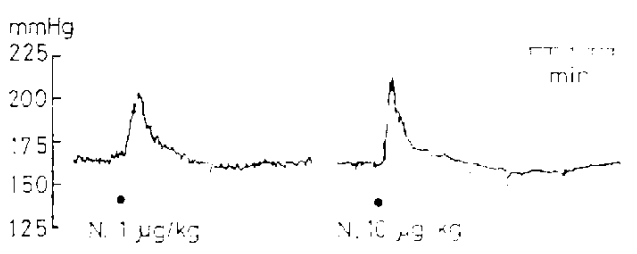

Fig. 1. Blood pressure responses to intraventricular nicotine ( $\mathrm{N}$.) in doses of $1 \mathrm{~kg} / \mathrm{kg}$ (left tracing) and $10 \mathrm{fg} / \mathrm{kg}$ (right tracing) in spontaneously hypertensive rats pretreated with methylatropine (1 $\mathrm{mg} / \mathrm{kg}, \mathrm{i} . \mathrm{v}$.). The time interval between the left and right tracing. 90 min. 
Table 1. Pressor responses to intraventricular nicotine after i.v. methylatropine (1 $\mathrm{mg} / \mathrm{kg}$ ) in spontaneously hypertensive (SHR), renal hypertensive (RHR). DOCA-saline hypertensive (DHR), normotensive Wistar Kyoto (WKR) and normotensive Wistar (NR) rats.

\begin{tabular}{|c|c|c|c|}
\hline & \multirow{2}{*}{$\begin{array}{l}\text { Arterial pressurea } \\
\quad(\mathrm{mmH})\end{array}$} & \multicolumn{2}{|c|}{ Pressor responses to nicotine $(\mathrm{mmHg})$} \\
\hline & & $1 / \mu \mathrm{g} / \mathrm{kg}$ & $10 \mathrm{rg} / \mathrm{kg}$ \\
\hline $\operatorname{SHR}(n=10)$ & $153+1^{*}$ & $41 \pm 2^{*}$ & $58 \pm 2^{*}$ \\
\hline WKR $(\Pi=10)$ & $121 \pm 1$ & $8 \pm 2$ & $20 \pm 3$ \\
\hline $\operatorname{RHR}(n=8)$ & $166 \pm 6^{*}$ & $11 \pm 1$ & $22 \pm 2$ \\
\hline DHR $(n=8)$ & $176 \pm 9^{*}$ & $7 \pm 2$ & $25 \pm 4$ \\
\hline$N R(n=10)$ & $121 \pm 1$ & $8 \pm 2$ & $21 \pm 3$ \\
\hline
\end{tabular}

a Each value represents the meantS.E. n-number of experiments. "Statistically significant $P<0.001$ aganst the respective normotensive controls.

Table 2. Pressor responses to intraventricular nicotine (1//g/kg) before and after intraventricular administration of cholinoceptor antagonists in methylatropine (1 $\mathrm{mg} / \mathrm{kg} \mathrm{i.v.)} \mathrm{-}$ treated spontaneously hyportensive rats.

\begin{tabular}{|c|c|c|c|c|c|}
\hline \multirow[t]{2}{*}{ Treatment } & \multirow{2}{*}{$\begin{array}{l}\text { No. of } \\
\text { oxps }\end{array}$} & \multicolumn{2}{|c|}{$\begin{array}{l}\text { Arterial pressure } \\
\text { (mmHg)il }\end{array}$} & \multicolumn{2}{|c|}{$\begin{array}{l}\text { Pressor responses to } \\
\text { nicotine (mmHg): }\end{array}$} \\
\hline & & Before & After & Before & After \\
\hline None & 5 & $155 \pm 1$ & $154 \pm 1$ & $38+2$ & $35 \pm 3$ \\
\hline Hexamothonium $(10, \mu \mathrm{g} / \mathrm{kg})$ & 5 & $153+2$ & $154 \pm 2$ & $39 \pm 4$ & $3 \pm 2^{*}$ \\
\hline Atropine $(100: / \mathrm{g} / \mathrm{kg})$ & 5 & $154 \pm 3$ & $156 \pm 3$ & $40 \div 3$ & $40 \pm 4$ \\
\hline
\end{tabular}

a Each value represents the mean \pm S.E. *Statistically significant $P<0.001$ against control values.

and hypertensive rats to intraventricular nicotine were too small $(3-8 \mathrm{mmHg})$ for comparison. Intraventricular administration of the vehicle produced no appreciable changes in blood pressure in these normotensive and three types of hypertensive rats. In another five paired experiments, 6 -monthold male SHR and WKR were compared. Nicotine $(10 \mathrm{mg} / \mathrm{kg})$ administered i.v.c. to SHR produced an increase of $62 \pm 5 \mathrm{mmHg}$ in blood pressure, as compared with $19 \pm 4$ $\mathrm{mmHg}$ in WKR ( $\mathrm{P}<0.001)$.

Vascular response to intraventricularly injected nicotine before and after central administration of cholinergic antagonists in SHR: When nicotine $(1 / 6 \mathrm{~g} / \mathrm{kg})$ was administered into the lateral ventricle of SHR brain at intervals of $90 \mathrm{~min}$, the blood pressure responses wore much the same (Table 2).
Hexamethonium $(10 / \mathrm{gg} / \mathrm{kg})$ given i.v.c. $10 \mathrm{~min}$ before the second administration of nicotine all but abolished the blood pressure response to nicotine.

Atropine $(100 \mathrm{rg} / \mathrm{kg})$ given i.v.c. $10 \mathrm{~min}$ before the second administration of nicotine had no effect on blood pressure response to nicotine. These cholinergic antagonists did not affect the basal blood pressure.

Vascular response to intraventricularly administered nicotine after central administration of phentolamine and 6-hydroxydopamine in SHR: Phentolamine $(50 \mu \mathrm{g})$ was intraventricularly administered $60 \mathrm{~min}$ before the microinjection of nicotine into the lateral ventricle of SHR brain. The $\alpha$-adrenergic blocking agent produced no appreciable effect on the basal blood pressure and pressor response to nicotine $(10 \mu \mathrm{g} / \mathrm{kg})$ after 
i.v. methylatropine $(53 \pm 4 \mathrm{mmHg}, \mathrm{n}=4)$. In 6 experiments, rats were given 6 -hydroxydopamine $(250 \mu \mathrm{g})$ i.v.c. 3 days before the dosing with nicotine. No significant difference in the basal blood pressure $(155 \pm 2$ $\mathrm{mmHg}$ ) and the pressor response to $10 \mathrm{~kg} / \mathrm{kg}$ of nicotine $(56 \pm 4 \mathrm{mmHg})$ was seen in the centrally sympathectomized SHR, as compared to findings in the untreated SHR, as shown in Table 1.

Vascular response to intraventricularly injected nicotine after bilateral adrenalectomy and/or peripheral administration of 6-hydroxydopamine in SHR: To determine whether or not the adrenal medulla participates in the development of the pressor response to nicotine, bilateral adrenalectomy was performed 3-4 hr before the experiments. Under these experimental conditions, pressor responses to intraventricular administration of nicotine ( 1 and $10 \mu \mathrm{g} / \mathrm{kg}$ ) in SHR after i.v. methylatropine were significantly reduced (Table 3). In 5 experiments, 6-hydroxydopamine $(100 \mathrm{mg} / \mathrm{kg})$ was given i.p. $24 \mathrm{hr}$ before the experiments. Removal of adrenal glands in the 6-hydroxydopamine-treated SHR abolished the pressor response to nicotine $(10, \mathrm{gg} / \mathrm{kg})$ given i.v.c. after i.v. methylatropine (Table 3). Although treatment with periphera! 6-hydroxydopamine and bilateral adrenalectomy lowered basal blood pressure to $62 \pm 4 \mathrm{mmHg}$, i.v. administered noradrenaline $(1 / \mathrm{gg} / \mathrm{kg})$ still produced a greater pressor response $(121 \pm 7 \mathrm{mmHg})$.

Table 3. Effect of bilateral adrenalectomy on pressor responses to intraventricularly administered nicotine after i.v. methylatropine $(1 \mathrm{mg} / \mathrm{kg})$ in spontancously hypertensive rats.

\begin{tabular}{|c|c|c|c|}
\hline & $\begin{array}{l}\text { Arterial } \\
\text { pressure }(\mathrm{mmHg})^{n}\end{array}$ & \multicolumn{2}{|c|}{ Pressor responses to nicotine $(\mathrm{mmHg})$} \\
\hline Control $(10)$ & $153 \pm 1$ & $41 \pm 2$ & $58 \pm 2$ \\
\hline Adrenalectomy (7) & $155 \pm 2$ & $12 \pm 4^{*}$ & $33 \pm 4^{*}$ \\
\hline Adrenalectomy $(5)^{1,}$ & $62 \pm 4^{*}$ & & $0^{*}$ \\
\hline
\end{tabular}

a Each value represents the meaniS.E., ( ) number of experiments. b SHR treated with 6-hydroxydopamine $(100 \mathrm{mg} / \mathrm{kg}$, intraperitoneally) $24 \mathrm{hr}$ before experiments. - Statisticaliy significant $P<0.001$ against control value.

Table 4. Pressor responses to i.v. administration of nicotine, noradrenaline and adrenaline after i.v. methylatropine (1 $\mathrm{mg} / \mathrm{kg}$ ) in spontaneously hypertensive (SHR) and normotensive Wistar Kyoto (WKR) rats.

\begin{tabular}{lccc}
\hline Drugsa & & \multicolumn{2}{c}{ Pressor responses $(\mathrm{mmHg})^{\mathrm{b}}$} \\
Nicotine & 1 & SHR & WKR \\
Noradrenaline & 10 & 0 & 0 \\
& 0.25 & $7 \pm 2^{*}$ & 0 \\
Adrenaline & 1 & $32 \pm 3$ & $30 \pm 2$ \\
& 0.25 & $50 \pm 2$ & $48 \pm 3$ \\
& 1 & $36 \pm 4$ & $32 \pm 3$ \\
\hline
\end{tabular}

a Only one drug was tested in one rat. $b$ Each value represerits the mean \pm S.E. from 6-10 animals. "Statistically significant $P<0.01$ against $W K R$. 
Vascular response to intravenously administered nicotine, noradrenaline and adrenaline in SHR and WKR: To determine if leakage of nicotine into the periphery contributes to the cardiovascular responses to this alkaloid given intraventricularly, the effects of intravenously administered nicotine on blood pressure were examined after i.v. methylatropine $(1 \mathrm{mg} / \mathrm{kg})$. In SHR i.v. administration of nicotine $(1 / / \mathrm{g} / \mathrm{kg})$ did not affect blood pressure and a higher cose of nicotine $(10 / \mathrm{gg} / \mathrm{kg})$ produced only a slight increase in blood pressure. No noticeable changes in blood pressure were observed even after $10 \mathrm{hg} / \mathrm{kg}$ of nicotine were given intravenously to WKR (Table 4). Pressor responses to i.v. noradrenaline $(0.25$ and $1 \mu \mathrm{g} / \mathrm{kg})$ or i.v. adrenaline $(0.25$ and $1 \mu \mathrm{g} / \mathrm{kg}$ ) in SHR pretreated with i.v. methylatropine were much the same as those in WKR (Table 4).

\section{DISCUSSION}

The present study shows that the pressor response to intraventricularly administered nicotine is increased in SHR. This enhanced response appears to be specific for the genetic hypertension in SHR. since the response of renal hypertensive and DOCAsaline hypertensive rats was essentially the same as that of normotensive controls.

Even with a dose of $10 \% \mathrm{~g} / \mathrm{kg}$, i.v. nicotine had no effects on blood pressure in WKR and only slight pressor effects in SHR, indicating that the blood pressure responses to intraventricular nicotine are of central origin. Hexamethonium, a nicotinic receptor blocking agent, blocked pressor responses to intraventricular nicotine at the central receptors. In contrast, atropine, a muscarinic receptor blocking agent, was not an effective antagonist. Thus, the pressor response to centrally administered nicotine appears to be the result of a specific nicotinic mechanism.

It has been suggested that the pressor response to electrical stimulation of the posterior hypothalamus $(9,10)$ or to intraventricular angiotensin 11 administration (11) is mediated, in part, by central adrenergic mechanisms. In the present experiments, however, central phentolamine or 6-hydroxydopamine did not affect the pressor response to intraventricular nicotine. The dose of 6-hydroxydopamine used in our experiments was sufficient to cause a considerable destruction of central adrenergic neurons in rats (8). Phentolamine at one-fifth of the dose used in our experiments significantly reduced the pressor responses to noradrenaline given i.v.c. to rats (12). It seems therefore unlikely that central adrenergic mechanisms are involved in the nicotineinduced pressor response.

After removal of the adrenals, the pressor effect of intraventricular nicotine was markedly diminished in SHR. Thus, in SHR, activation of the central nicotinic receptor sites may produce a release of catecholamines from the adrenal medulla. In addition, peripheral 6-hydroxydopamine plus bilateral adrenalectomy abolished the pressor response to nicotine. This abolition of the pressor response may not result from the marked fall in basal blood pressure in those treated SHR, since i.V. noradrenaline contined to produce a rise in blood pressure. Thus, noradrenaline released from adrenergic nerve terminals also participates in the pressor response to central nicotine in SHR Moreover, pressor reactivity to i.v. catecholamines, noradrenaline and adrenaline, was almost the same in SHR and WKR. These findings may indicate that the enhanced pressor response to intraventricular nicotine in SHR results from an increase in catecholamine release from the adrenal medulla and adrenergic nerve terminals.

A recent study (5) demonstrated that i.v. administration of physostigmine caused a pressor response and this effect might 
involve central muscarinic mechanisms but not central nicotinic mechanisms. This finding seems to be incompatible with the present result that central nicotinic receptor stimulation also induces pressor responses. since physostigmine activates both muscarinic and nicotinic receptors. However, this may be due to differences in central sites of action of the drugs. Systemically administered physostigmine perfuses and affects sites in the brain which are reached only slowly. while intraventricular nicotine acts locally at neurons near the ventricles.

In conclusion, our findings indicate that SHR show an enhanced pressor response to centrally administered nicotine and that such may result from an increase in catecholamine release from the adrenal medulla and adrenergic nerve terminals. However, this finding does not enable determination of whether this alternation is involved in the pathophysiology of the genetic hypertension in SHR.

\section{REFERENCES}

1) Armitage, A.K. and Hall, G.H.: Further evidence relating to the mode of action of nicotine in the central nervous system. Nature 214, 977979 (1967)

2) Brezenoff, H.E. and Rusin, J.: Brain acetylcholine mediates the hypertensive response to physostigmine in the rat. Europ. J. Pharmacol. $29,262-266(1974)$

3) Bhargava, K.P., Jain, I.P., Saxena, A.K., Sinha, J.N. and Tangri, K.K.: Certrat adrenocoptors and cholinoceptors in cardiovascular control. Brit J. Pharmacol. 63, 7-15 (1978)

4) Krstic, M.K. and Djurkovic, D.: Cardiovascular response to intracerebroventricular administration of acetylcholine in rats. Neuropharmacology 17, 341-347 (1978)

5) Kubo, T. and Tatsumi, M.: Increased pressor responses to physostigmine in spontaneously hypertensive rats. Naunyn-Schmiedeberg's Arch. Pharmak. 306, 81-83 (1979)

6) Armitage, A.K. and Hall, G.H.: Effect of nicotine on the systemic blood pressure when injected into the cerebral ventricles of cats. Neuropharmacology 6, 143-149 (1967)

7) Kubo, T., Hashimoto, $M$. and Ohashi, $T$.: Effects of intraventricular and intraspinal 6 hydroxydoparine on blood pressure of renal rypertensive rats. Archs int. Pharmacodyn. Thér. 234, 270-278 (1978)

8) Kubo, T. and Hashimoto, M.: Effects of intraventricular and intraspinal 6-hydroxydopamine on blood prossure of DOCA-saline hypertensive rats. Archs int. Pharmacodyn. Thér. 238, 50-59 (1979)

9) Przuntek, H., Guimaraes, S. and Philippu, A.: importance of adrenergic neurons of the brain for the rise of blood pressure evoked by hypothalamic stimulation. Naunyn-Schmiedeberg's Arch. Pharmak. 271. 311-319 (1971)

10) Philippu, A., Roensberg, W. and Przuntek, $H$ : Effects of adrenergic drugs on pressor responses to hypothalamic stimulation. NaunynSchmiedeberg's Arch. Pharmak. 278, 373-386 (1973)

11) Smookler, H.H., Severs, W.B., Kinnard, W.J. and Buckley, J.P.: Contrally mediated cardiovascular effects of angiotensir. 11. J. Pharmacol. exp. Ther. 153, 485-494 (1966)

12) Hoffman, W.E., Schmid, P.G. and Phillips, M.I.: Central cholinergic and noradrenergic stimulation in spontaneously hypertensive rats. J. Pharmacol. exp. Ther. 206, 644-651 (1978) 